\title{
Studying the effect of existing technologies in a smart grid for reducing the distribution networks losses
}

\author{
Zahra Alizadeh \\ Sepehr Industrial Group Corporation, Ahwas, Iran
}

Email address:

Sg.sansgroup@gmail.com

To cite this article:

Zahra Alizadeh. Studying the Effect of Existing Technologies in a Smart Grid for Reducing the Distribution Networks Losses. Journal of Electrical and Electronic Engineering. Special Issue: Research and Practices in Electrical and Electronic Engineering in Developing Countries. Vol. 3, No. 2-1, 2015, pp. 16-20. doi: 10.11648/j.jeee.s.2015030201.14

\begin{abstract}
Nowadays, population growth and the electrical load demand on the one hand and rising cost of energy generation on the other hand have led to raises reducing the losses in distribution networks as a serious challenge. According to studies, smart grid is posed as the most important applicable solution to eliminate these problems. The purpose of this paper is to examine the impact of communication and information technologies and new control capabilities in smart grids for reducing distribution network dissipations. In this study, a new formulation and an optimal load flow algorithm are used to reduce losses in the smart distribution network. Optimal load flow for a 69-bus IEEE network as well as the installation of the smart network facilities are implemented in the MATLAB and GAMS software and the results show that distribution network losses are greatly reduced.
\end{abstract}

Keywords: Smart Network, Control Centers, Losses Reduction, Optimal Load Flow

\section{Introduction}

Increasing needs of electric power supply has made the transmission and distribution lines capacity insufficient in responding to the needs. Since the construction of new power plants and new transmission and distribution lines are not economically viable, power industry has been forced to cope with their problems by adding power, telecommunication and information technologies and new control features to networks and or in other words smart distribution transmission networks [1].

The different components of a distribution grid are shown in Figure 1. As it can be seen, most important infrastructures of distribution network include: distribution substations, control and protection devices, distributed energy resources, smart sensors and measurement devices and control center. Control center will be able to use telecommunications networks and interface equipment which has capabilities such as control, monitoring, protection, etc. receive information at each instant from various network components and issue desired control commands to them [2-9].

Also, the internal network components may also have some connections to control devices, regulating equipment, coordination between the substations, protection and control of sensors between themselves. Control centers of transmission and distribution networks have ability to exchange information between each other.

As it can be seen, by advancing power network structure and evolution in its nature, the necessity of control methods and new tools for network designing and analysis is revealed more than ever.

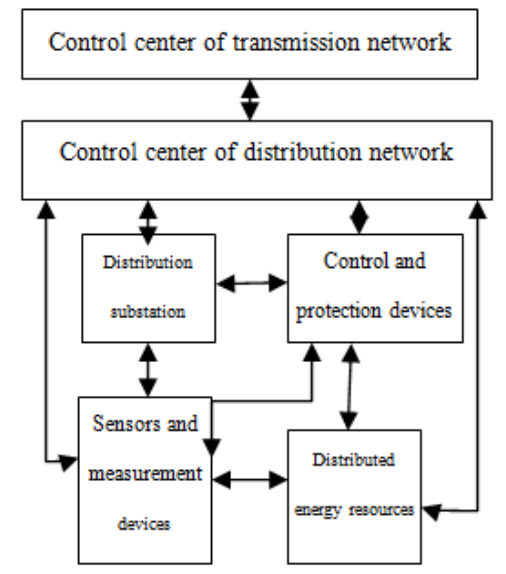

Figure 1. Different components of a smart distribution network [1]

Several research studies [10-16], optimal load flow algorithms for distribution networks are presented in order to reduce power losses and improve the voltage profile where the 
presence of physical network components such as dispersed generations and controllers based on power electronics devices are addressed.

In this paper, a new algorithm is presented for optimal load flow that can determine the favorable conditions to exploit a smart network with all its new features, including the presence of ICT systems. In this algorithm, role of distribution and transmission control centers is very significant. In this formulation, the active and reactive powers of transmission network loads, that can be smart distribution networks themselves and exchange power with transmission network bi-directionally, are considered as control and state variables which determine their values control center. In fact, a series for the new control and state variables for formulations related to optimal load flow is introduced that determines their values control centers immediately.

The presented algorithm is implemented for an IEEE 69-bus network in which smart network equipment are installed which its results show reduction in the network power losses.

\section{The Optimal Load Flow Formulation in a Smart Grid}

The optimal load flow formulation in a smart network will be according to equations 1 through 3 :

$$
\begin{gathered}
\operatorname{Min}_{u, s} \operatorname{cobj}\left(x, u, x_{s}, u_{s}\right) \\
f\left(x, u, x_{s}, u_{s}\right)=0 \\
g\left(x, u, x_{s}, u_{s}\right) \prec 0
\end{gathered}
$$

Where Cobj is the objective function, $\mathrm{x}$ is the state variable vector in a traditional network, xs state variable vector in the smart network, $u$ the control variable vector in the traditional network and us control variable vector in the traditional network and smart network. In fact, the control and state variables are divided into two categories, first are control variables and traditional network state $(\mathrm{x}, \mathrm{u})$ whose values are determined according to the conventional characteristics of the power networks. The second are the control and state variables related to the smart network (us, xs) whose values are determined by smart control centers through real-time received data from operators immediately.

\subsection{Introducing the Objective Functions}

The objective function we have considered in the distribution network is minimizing the total lines losses.

$$
c_{o b j}=\min \left(\sum_{l=1}^{n l} p_{l}\right)
$$

So that $\mathrm{Pl}$ is active power losses in Lth line and $\mathrm{L}$ is number of lines. But the active power losses in each distribution lines are derived according to Equation 5.

If we consider a part of the distribution network like
Figure 2, that power flowing from bus $\mathrm{i}$ to the line is $(\mathrm{Si}=\mathrm{Pi}$ $+\mathrm{jQi})$ and received power at bus $\mathrm{j}$ equals $(\mathrm{Sj}=\mathrm{Pj}+\mathrm{jQji})$ and amount and angle of voltages in source and destination buses, respectively, from $\delta_{i}, \mathrm{vi}, \delta_{j}, \mathrm{vj}$, We have:

$$
\operatorname{Plosses}_{(i, j)}=\frac{r_{i-j}\left(P_{j}^{2}+Q_{j}^{2}\right)}{V_{j}^{2}}
$$

The active power losses between buses $i$ and $j, r(i, j)$ is the resistance between buses $i$ and $j, \mathrm{Vj}$ is voltage at bus $\mathrm{j}$ and $\mathrm{Pj}$ and $\mathrm{Qj}$ are active and reactive powers at bus $\mathrm{j}$ respectively.

Equality and inequality constraints on the transmission line connected to the distribution network according to reference [17] and relationships related to the amount and angle of the reference voltage have been determined according to [18].

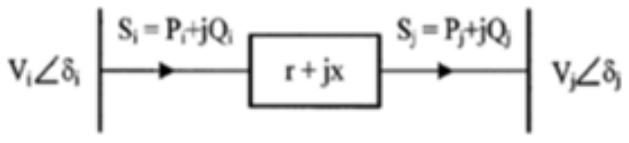

Figure 2. A part of radial distribution network.

\section{Optimal Load Flow Algorithm in a Smart Distribution Network}

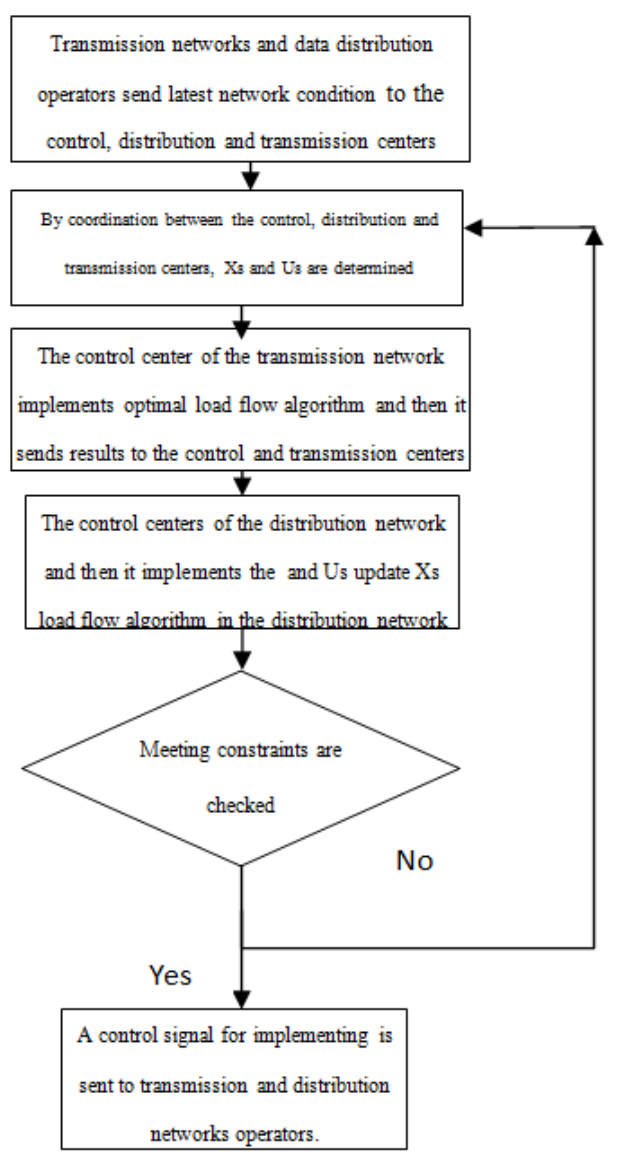

Figure 3. The optimal load flow algorithm in a smart network.

In this study, backward and forward sweep method for optimal load flow in a smart distribution network is used. 
Because this method has high operation speed and will be appropriate in the smart network whose control center will be able to receive real-time data and do optimal load flow in a short time to do. The distribution control center determines $\mathrm{Xs}$ and Us based on received data, again and implements optimal load flow in the distribution network.

If at this step, all the objective functions and constraints are met, the results of load flow are sent to the transmission and distribution networks operators. Otherwise, Us and Xs should be determined by coordination between distributed and transmission control centers, again.

Transmission networks and data distribution operators send latest network condition to the control, distribution and transmission centers

By coordination between the control, distribution and transmission centers, Xs and Us are determined.

The control center of the transmission network implements optimal load flow algorithm and then it sends results to the control and transmission centers

The control centers of the distribution network update Xs and Us and then it implements the load flow algorithm in the distribution network.

\section{The Studied Network}

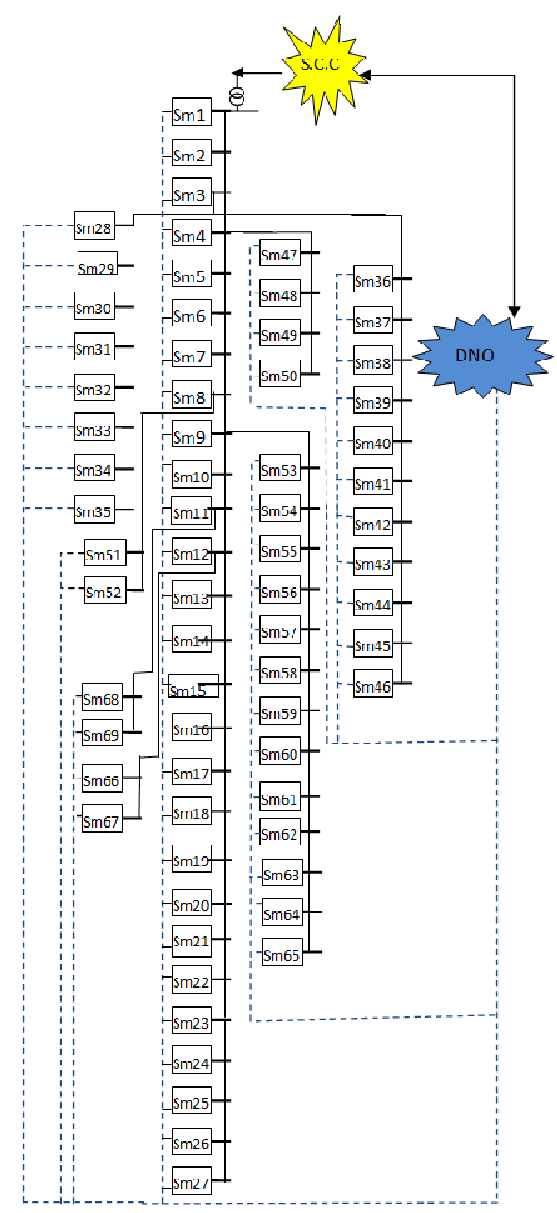

Figure 4. 69 buses IEEE radial distribution network that convert to smart distribution grid \& smart control center could manage system through $\mathrm{DNO}$ (SM is abbreviate of smart meter).
The studied network is an IEEE standard 69-bus radial distribution network (Figure 4) in which the smart network equipment are installed. Including the equipment, smart meter ( $\mathrm{sm})$ can be noted as well as the load centers.

Operator of the distribution network will be able to receive total real-time data through telecommunication lines which are shown by dashed lines and send them to the control center for analysis and implement commands issued by the control center in the entire network. Also, this distribution network has possibility to exchange the power with the transmission network in two directions.

\section{Simulation Results}

In this section, the results of the optimal load flow have been studied in each of the active distribution networks, in four different modes. In the first case, we assume that the distribution network is not a distribution network originally and can only receive energy from the transmission network. In the second case, dispersed generations are installed in a distribution networks and the control center allows the operator to feed the network as an island. In the third case, not only dispersed generations are installed in the distribution network, but the distribution network operator can exchange energy with the transmission network. The fourth case is similar to the third, but the difference is that in the fourth case, exchanged power between the transmission network and the distribution network is set by the presence of existing information and communication technologies in the smart networks and coordination between operators and the control centers of distribution and transmission networks such that The active power losses become minimal in the distribution network. The DG capacity installed at bus no.14 is $750 \mathrm{KW}$ and the DG capacity installed at bus no.65 is $1.65 \mathrm{MW}$. Optimization in fourth case is possible by virtue of the connection between MATLAB and GAMS software.

MATLAB software transfers loads of flow data to the GAMS software and GAMS sets imported energy from transmission lines to the distribution network in a way that the distribution lines losses will be minimal, according to Equation 4.

GAMS software employs a non-linear programming method with discontinuous derivatives in optimization.

The voltage profile is shown in Figures 5 to 8 . As shown in Figures 9 and 10, the minimum voltage is in each case as follows respectively: 0/913,0/943, 0/95. and 0/945 Pu. And the active power losses are $200 \mathrm{~kW}, 160 \mathrm{~kW}, 230 \mathrm{~kW}$ and $190 \mathrm{~kW}$ respectively. As you can see in the fourth case, in presence of the information and communications technology systems that have possibility of establishing a bi-directional connection between the control and operations centers than the third case that because the lack of required technology, there was no possibility of the flexibility in the exchanged power between the transmission and distribution, distribution lines losses has fallen by about 20 percent. 


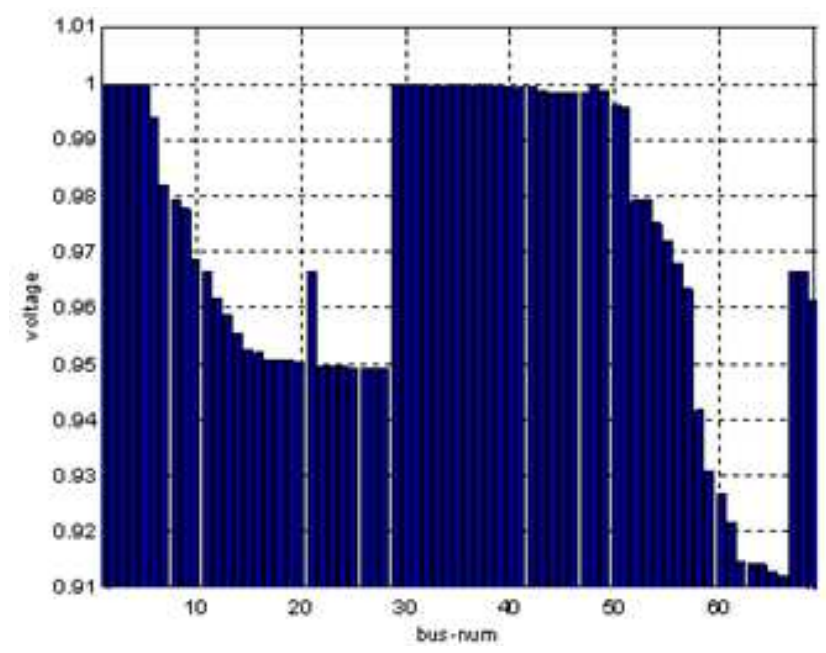

Figure 5. The voltage profile of 69-buses IEEE radial distribution system (first state)

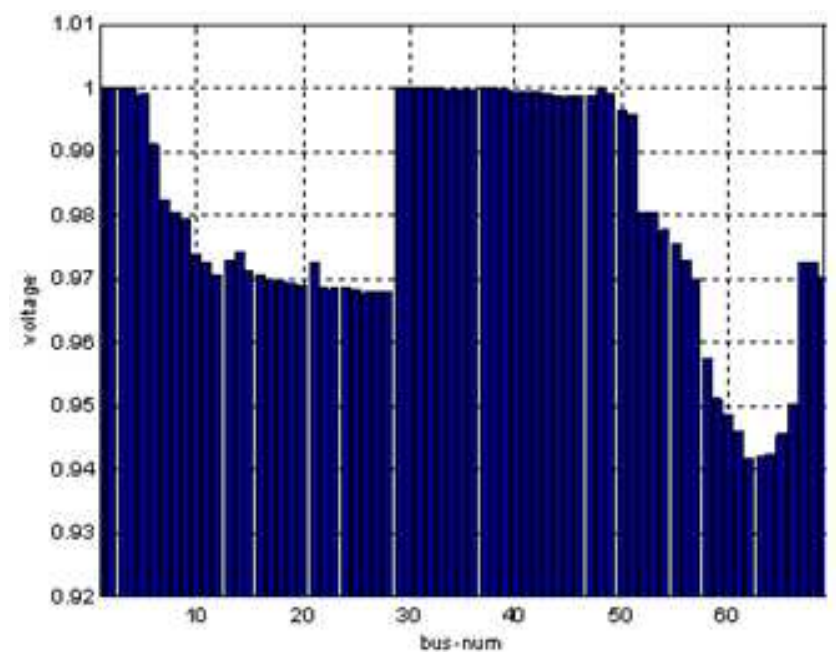

Figure 6. The voltage profile of 69-buses IEEE radial distribution system (second state)

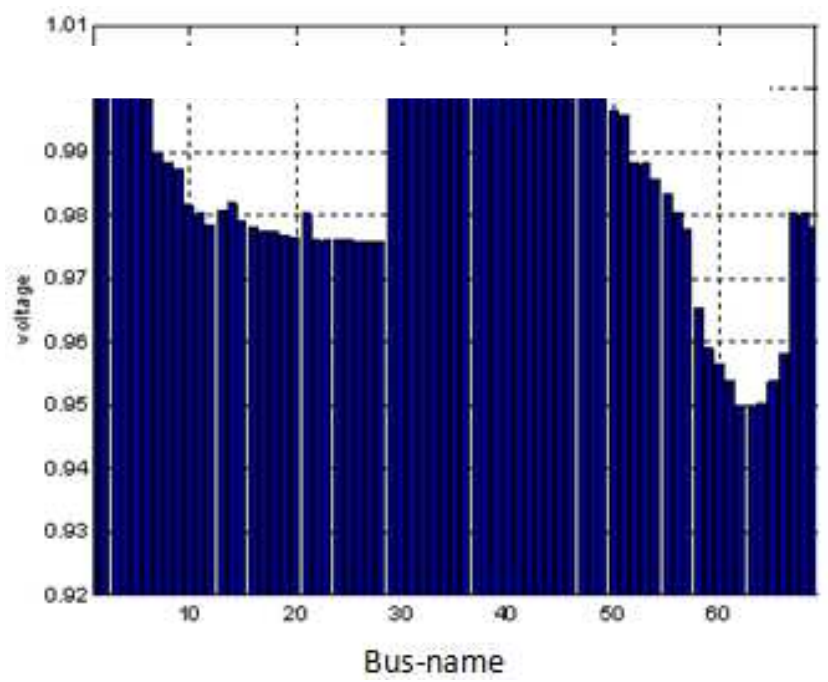

Figure 7. The voltage profile of 69-buses IEEE radial distribution system (second state)

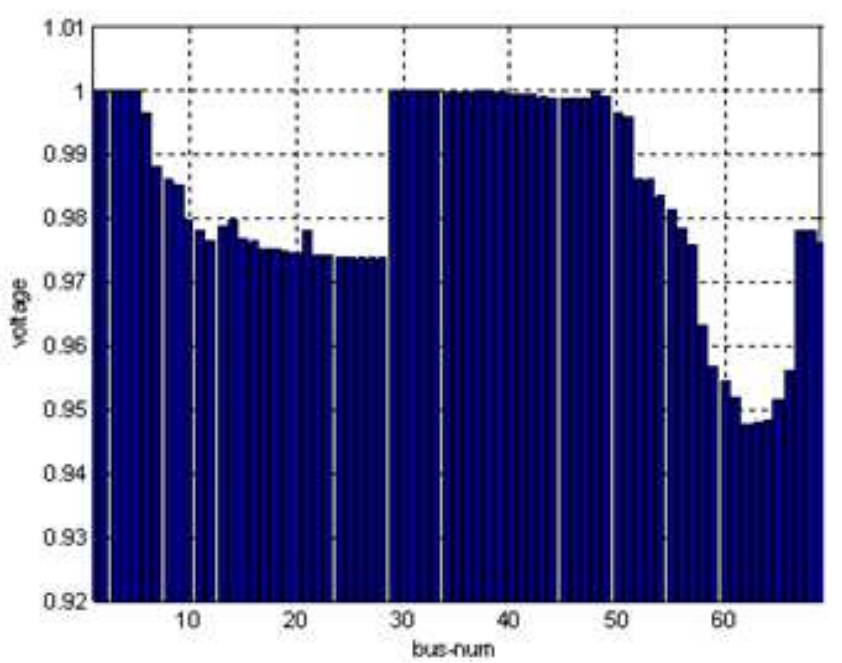

Figure 8. The voltage profile of 69-buses IEEE radial distribution system (fourth state)

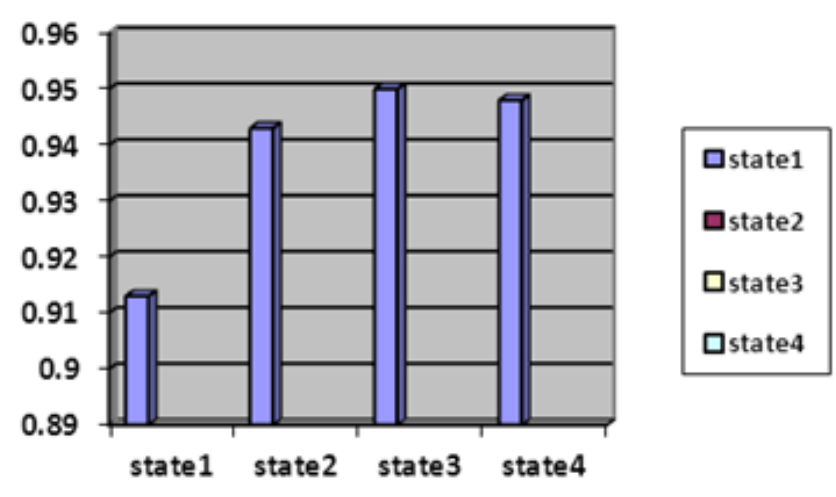

Figure 9. Comparison of the minimum voltage at 4 different cases

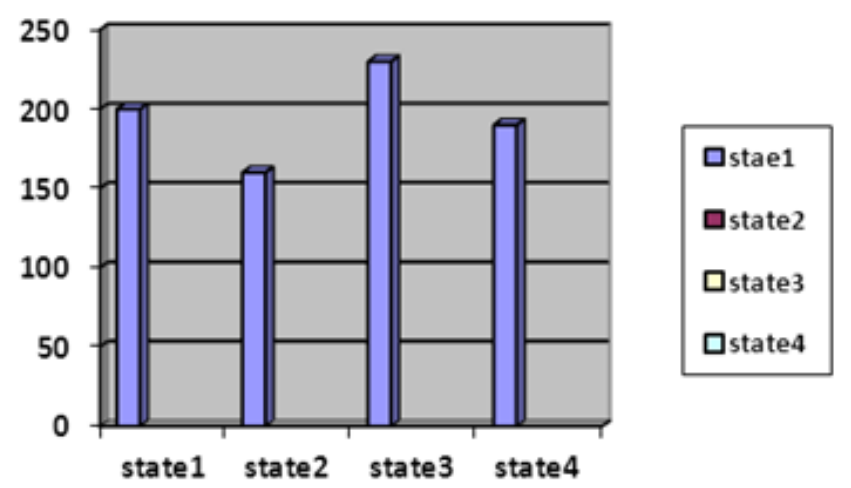

Figure 10. Comparison of active power losses in the network at 4 cases in $\mathrm{kW}$

\section{Discussion and Conclusion}

Due to the reason that the conventional electricity network structure does not meet the increasing requirement for electric energy, the smart network, as an economical solution is raised to solve this problem. By advancing network and adding infrastructures such as dispersed generation resources, smart control centers, information and communication technologies and smart meters, more advanced computational algorithms are required for load flow control in the network to be consistent with the new infrastructures. 
In this paper, an attempt has been done to show impact of control centers of smart transmission and distribution in the variables (xs.us), in the optimal load flow formulation. Furthermore, an optimal load flow algorithm was presented which can contain communication between the smart control centers together and with the network operators. In the algorithms that have been mentioned in previous sections, the presence of the physical components of the smart networks such as dispersed generations were considered to lower losses, but here, in addition to the physical components, the special attention has been made to the presence of the information and communication technology systems of the smart networks and special. Then the algorithm for a of 69-bus IEEE standard network was implemented in which all smarting network equipment are installed.

The results showed that the distribution network losses have been reduced about $20 \%$.

\section{References}

[1] IEEE Guide for Smart Grid Interoperability of Energy Technology and Information Technology Operation with the Electric Power System (EPS), End-Use Applications, and Loads. IEEE Std 2030, 2011

[2] Second of the NIST Framework and Roadmap for Smart Grid Interoperability Standards, National Institute of Standards and Technology, October, 2011

[3] Telvent utilities group, "the advanced distribution management system" The indispensable tool of the Smart Grid era, August 2010, www.telvent.com/smartgrid | 1.866.537.1091

[4] Pei Zhang, Fangxing Li, Navin Bhatt "Next-Generation Monitoring, Analysis, and Control for the Future Smart Control Center" IEEE Transactions on smart grid, VOL. 1, NO. 2, September 2010

[5] Fangxing Li, Wei Qiao, Hongbin Sun, Hui Wan , Jianhui Wang, Yan Xia , Zhao Xu, Pei Zhang " Smart Transmission Grid: Vision and Framework" IEEE Transactions on smart grid, VOL. 1, NO. 2, September 2010.

[6] James A. Momoh "Smart Grid Design for Efficient and Flexible Power Networks Operation and Control" pp. 1-8,(March 2009),

[7] Anjan Bose, "Smart transmission grid applications and their supporting infrastructure" This paper appears in: Smart Grid, IEEE Transactions on, Volume: 1, Issue: 1, Page(s): $11-19$, June 2010

[8] Chun-Hao Lo, Nirwan Ansari "The Progressive Smart Grid
System from Both Power and Communications Aspects" This paper appears in: Communications Surveys \& Tutorials, IEEE Third Quarter Volume: 14, Issue: 3 Page(s): 799 - 821, 2012.

[9] M.E. Baran, F.F. Wu, "Optimal sizing of capacitor placed on radial distribution systems", IEEE Transactions on Power Delivery, vol. 4, num. 1, pp. 735-743, 1989

[10] A. Rost, B. Venkatesh and C. P. Diduch" Distribution System with Distributed Generation Load Flow" Department of Electrical and Computer Engineering New Brunswick, NB, Canada, 2008

[11] A. Milo, A. Martinez, M. Rodríguez, A. Goikoetxea" Dynamic power flow tool development for low voltage networks analysis with high penetration level of distributed generation" Renewable Energy \& Power Quality Journal, March 2008.

[12] K. Vinoth Kumar, M.P. Selvan, "A Simplified Approach for Load Flow Analysis of Radial Distribution Network" International Journal of Computer and Information Engineering 2:4, 2008.

[13] M.Kowsalya, K.K.Ray, Udai Shipurkar, and Saranathan" Voltage Stability Enhancement by Optimal Placement of UPFC" 310 Journal of Electrical Engineering \& Technology Vol. 4, No. 3, pp. 310 314, 2009.

[14] M.Padma lalitha,N.Sinarami reddyv,C. Veera reddy " Optimal $\mathrm{dg}$ placement for maximum loss reduction in radial distribution system using abc algorithm" International journal of reviews in computing, 2009-2010

[15] M. Ravichandra Babu, D. Mary" Power Loss Minimization for Power Quality Radial Distribution System" European Journal of Scientific Research Vol.78, pp.507-521, (2012)

[16] A. Lashkar Ara, A. Kazemi, S. A. Nabavi Niaki, Multiobjective"Optimal Location of FACTS Shunt-Series Controllers for Power System Operation Planning" IEEE Transactions on power delivery, Page(s): 481 - 490,2012

[17] Stephan Koch, Göran Andersson," Implementation and evaluation of a distribution load flow algorithm for networks with distributed generation" Semester Work, Vanco Janev, EEH - Power Systems Laboratory, Swiss Federal Institute of Technology, Zurich, in March 2009

[18] Jiaqi Liang, Ronald G. Harley, Ganesh K. Venayagamoorthy" Adaptive Critic Design based Dynamic Optimal Power Flow Controller for a Smart Grid" Computational Intelligence Applications In Smart Grid (CIASG), Page(s): 1 -8, IEEE Symposium on 11-15 April 2011

[19] Sumit Paudyal, Claudio A. Ca nizares, Kankar Bhattacharya" Optimal Operation of Distribution Feeders in Smart Grids"Smart Grid, IEEE Transactions on, Volume: 3 Page(s): $59-69$, March 2012 